\title{
TROPICAL FOREST REMOTE SENSING SERVICES FOR THE DEMOCRATIC REPUBLIC OF CONGO INSIDE THE EU FP7 'RECOVER' PROJECT (FINAL RESULTS 2000-2012)
}

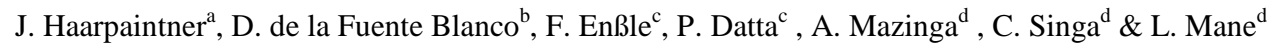 \\ ${ }^{a}$ Norut, P.O. Box 6434, Tromsø Science Park, N-9294 Troms ø, Norway - joergh@ norut.no \\ ${ }^{\mathrm{b}}$ GMV, Calle Isaac Newton 11, Tres Cantos, E-28760 Madrid, Spain \\ ${ }^{c}$ Albert-Ludwigs University Freiburg, Tennenbacher Straße 4, D-79106 Freiburg, Germany \\ d OSFAC, 14 Av. Sergent Moke (Q. Socimat), Concession Safricas, Ngaliema / Kinshasa, DRC
}

THEME: BIOD - Forests, Biodiversity and Terrestrial Ecosystems.

KEY WORDS: REDD+, Forest, Forest Change, SAR, Congo Basin.

\begin{abstract}
:
'ReCover' was a 3-year EU-FP7 project (Nov. 2010 - Dec. 2013), aiming to develop and improve science based remote sensing services to support tropical forest management and activities to reduce emission from deforestation and forest degradation (REDD) in the tropical region (Häme et al., 2012). This is an overview of the final ReCover service delivery of 2000-2012 single-year optical (Landsat, ALOS AVNIR-2, RapidEye) and C-and L-band SAR (Envisat ASAR and ALOS Palsar, respectively) image mosaics, their derived forest/non-forest maps, a multi-sensor forest change map (2000-2010) and a biomass map (based on 2003-2009 ICESat GLAS) to the user of the Democratic Republic of Congo (DRC), the Observatoir Satellitale des Forêts d'Afrique Centrale (OSFAC). The results are an improvement from a first iteration service delivery in 2012 after a critical review and validation process by both, the user and service providers, further method development and research, like a prior statistical data analysis considering temporal/seasonal variability, improved data pre-processing, and through the use of ground reference data collected in March 2013 for classification training. Validation with Kompsat-2 VHR data for the 2010 forest/non-forest maps revealed accuracies of $87 \%$ and $88 \%$ for optical and radar sensors, respectively.
\end{abstract}

\section{INTRODUCTION}

The Congo Basin has been subject to extensive systematic forest monitoring using mainly optical satellite sensors, i.e. MODIS and Landsat (Hansen et al., 2008). This work resulted in a complete DRC forest atlas, FACET (Forêts d'Afrique centrale évaluées par télédétection) published by OSFAC and South Dakota State University (OSFAC, 2010). Global annual Landsat-based systematic forest monitoring results based on (Hansen et al., 2013) are now available online through Global Forest Watch (http://www.globalforestwatch.org/).

ReCover was a 3-year EU FP 7 project (Nov. 2010 - Oct. 2013) led by VTT Technical Research Centre of Finland aiming to develop and improve science based remote sensing services to support tropical forest management and activities to reduce emission from deforestation and forest degradation (REDD) in the tropical region (Häme et al, 2012). The remote sensing services are developed according to specific user requirements that are expressed through Service Level Agreements (SLA) between the ReCover consortium and six users from five different countries: Colombia, the Democratic Republic of Congo (DRC), Fiji, Guyana, and Mexico. The Observatoir Satellitale des Forêts d'Afrique Centrale (OSFAC) is one of these users representing the case of DRC. The team in charge for the service to OSFAC was composed by its lead, Norut (Norway), and partners, GMV (Spain) and Albert-LudwigsUniversität Freiburg (ALU-FR, Germany). The work load of the service was divided according to their main skills, synthetic aperture radar (SAR) based monitoring (Norut), optical satellite monitoring (GMV \& ALU-FR), biomass estimation (ALU-FR) and web-based geographic information system (GMV).
The service products delivered are: a) optical and SAR image mosaics, b) optical and SAR based forest/non-forest maps (FNF), c) biomass maps, and d) forest change maps. The service delivery happened in two iterations; the first iteration products delivered in 2012 were based on a first adaption of already used or developed methods by the partners (Haarpaintner et al., 2012; Einzmann et al., 2012; Pedrazzani et al., 2012), the second iteration and final products delivered in summer 2013 should be an improvement through a critical review and validation process and by further method development.

In this paper we will give an overview of the main final ReCover service products for the time period 2000-2012 to OSFAC presenting shortly the region of interest, the different products with a brief description of the methods applied including the improvements since the first product delivery iteration and the validation results and assessment.

\section{THE REGION OF INTEREST}

The region of interest and service area of about $68000 \mathrm{~km}^{2}$ is located in the west of DRC, bounded by $0^{\circ} 03^{\prime} \mathrm{N}$ and $3^{\circ} 15^{\prime} \mathrm{S}$, the Congo River in the west and Lake Mai-Ndombe (18 $\left.30^{\circ} \mathrm{E}\right)$ in the east (Fig.1). The study area belongs to the humid tropics. The northern part has low seasonal variations whereas the south has a dry season between June and August. Beside primary tropical and secondary forest the land is covered by swamp, flooded forest as well as patches of savannah and upland forest. Deforestation is taking place in several regions especially in the southern part. 

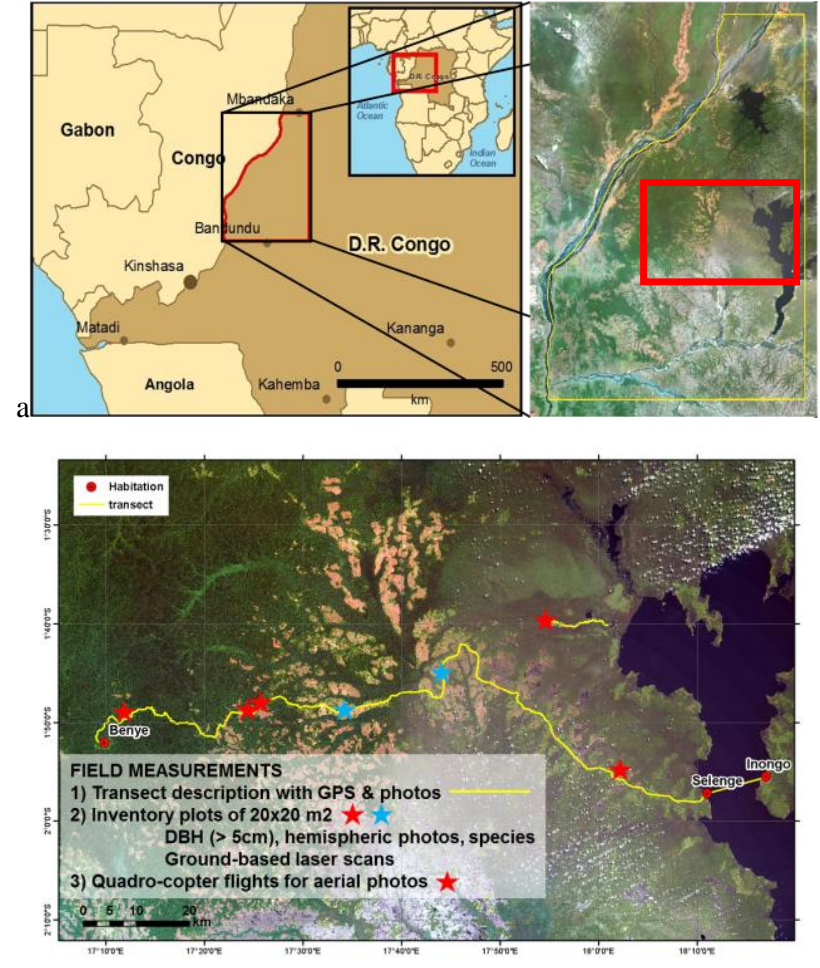

$\mathrm{b}$

Figure 1: (a) ReCover service area in DRC of about $\sim 68000$ km2 bounded by Congo River (west), Lake Mai Ndombe (18 $\left.30^{\prime} \mathrm{E}\right)$, cities of Mbandaka $\left(0^{\circ} 03^{\prime} \mathrm{N}\right)$ and Bandundu $\left(3^{\circ} 15^{\prime} \mathrm{S}\right)$. (b) Transect and forest plot sites of the fieldwork area (red rectangle in zoom of 1a).

A field campaign was carried out during 18-26 March 2013 along the road R204 from Inongo/Selenge to Benye in the MaiNdombe district as well as by boat in an inundated forest region in the North-west of Lac Mai-Ndombe (yellow lines in Fig 1c). There are many settlements and villages along the road. The eastern half of the road goes through mainly secondary forest with wet grasslands and swamp forest. Primary forests are mainly towards the west which also shows more areas covered by dry savannah. Seven field plots have been visited during the campaign (blue and red stars in Fig 1b) and aerial photos have been taken over five of them (red stars in Fig 1b) (Haarpaintner \& Enßle, 2014).

\section{SERVICE PRODUCTS}

The service delivery and products shown in this paper are satellite image mosaics and their corresponding FNF maps for the years 2000, 2005 and 2010, a 2000-2010 forest change map, and a best practice biomass map based on ICESat GLAS. All products are on the same UTM zone $33 \mathrm{~S}$ and use the same $30 \mathrm{~m}$ grid for alignment.

\subsection{Image Mosaics}

Image mosaics were produced for the approximate years 2000, 2005 (only SAR) and 2010.

\subsubsection{Optical image mosaics for 2000 and 2010}

Optical image mosaics based on Landsat (2001), ALOS Avnir-2 (2010) and RapidEye (2012) were produced and are shown in Fig 2. Optical data present problems due to cloud, mist and haze. In the second iteration of the ReCover project, the mosaic compilation was further improved by applying corrections and improved cloud masking. Geometric and basic atmospheric corrections based on (Chavez, 1996) have been applied on the Landsat and ALOS Avnir-2 data. RapidEye data was added during the second phase of ReCover to the production chain and is thus provided for the first time in the project.

The Landsat mosaic was aimed to provide data for the year 2000. Due to the serious problem of high and frequent cloud coverage it was required to use sets of scenes which are as close as possible to the envisaged years, i.e. 2001 data from Landsat-7 ETM+. Since a mosaic is created to give the best visual appearance and perceptibility, a histogram matching of the single bands and between the scenes were carried out in order to match the overall colour and shading between the images before mosaicking.

The mosaic issues for ALOS Avnir-2 for the year 2010 were that about $10 \%$ of the region was covered by clouds and mist and reflectance values varied considerably between one image and the other (i.e. different seasons and angle of acquisition). After several tests the best result were obtained by mosaicking part by part by means of mainly bilinear resampling methods. To guarantee homogeneity of results when delivering classification maps and change detection information the ALOS Avnir-2 data were reduced from its original $10 \mathrm{~m}$ to $30 \mathrm{~m}$ resolution.

The RapidEye mosaic for 2012 consisted of 158 ortho-rectified tiles (level $3 \mathrm{~A}$ product) of $25 \mathrm{~km}$ by $25 \mathrm{~km}$ and $5 \mathrm{~m}$ by $5 \mathrm{~m}$ pixel size. Acquisition dates range from 22.01.2011 to 23.02.2013 and cover different seasons of the year. A historical set of MODIS reflectance data (MOD09GA) was used to improve the radiometric calibration of wall-to-wall data before mosaicking. Cloudy areas were manually masked out and the entire mosaic was computed by histogram matching without colour corrections at $10 \mathrm{~m}$ spatial resolution. To be in line with other products, the mosaic was also resampled to $30 \mathrm{~m}$.

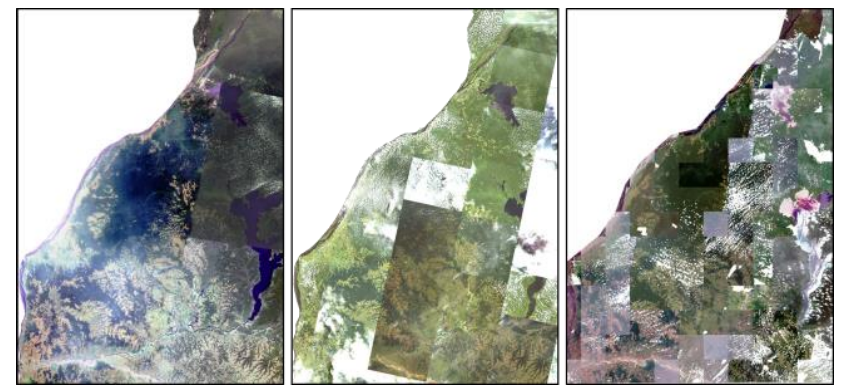

Figure 2: (left) 2001 Landsat mosaic. (middle) ALOS Avnir-2 mosaic (2010) and (right) RapidEye mosaic (2012). 


\subsubsection{SAR image mosaics for years 2000,2005 and 2010} The SAR image mosaics are based on ERS-2 SAR for year 2000, Envisat ASAR wide-swath (ASAR WS) for 2005, Envisat ASAR alternate polarization (ASAR APS) and ALOS Palsar Fine-Beam-Dual polarization (FBD) both dual-polarization for 2010 (Fig. 3). SAR pre-processing, i.e. georeferencing, radiometric calibration and slope correction, has been done with Norut's in-house developed GSAR software (Larsen et al., 2005) using the SRTM.v4 DEM. An advanced sigma nought $\left(\sigma^{\circ}\right)$ correction was introduced to the pre-processing in order to account for an angle dependency of the illuminated area, according to Shimada \& Takahiro (2010) and Ulander (1996).

The ERS-2 single year mosaic (Fig 3 upper left) was built by averaging 22 acquisitions of the year 1999-2001 in order to reduce speckle and seasonal effects. Only areas with ellipsoidal incidence angles between $20.98^{\circ}$ and $25.06^{\circ}$ were considered within the averaging process.

The 2005 mosaic is a mean backscatter image from nine ASAR WS images in VV polarization (Fig 3 upper right). This temporal averaging reduces speckle effects and improves the $30 \mathrm{~m}$-subsampling information content from the native WS mode resolution of approximately $90 \mathrm{~m}$.
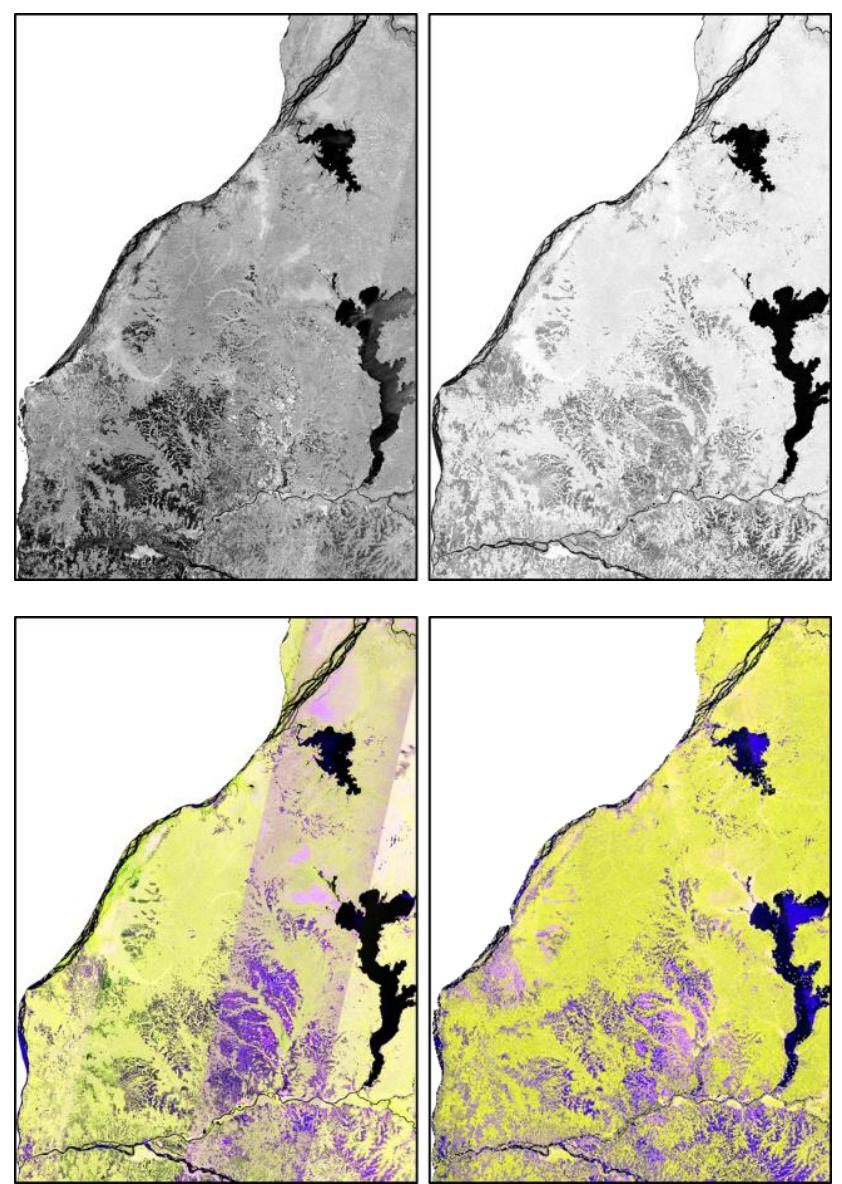

Figure 3. SAR mosaics based on 2000 ERS-2 SAR (UL), 2005 Envisat ASAR WS (UR), Envisat ASAR APS with $\mathrm{RGB}=[\mathrm{VV}, \mathrm{VH}, \mathrm{NDI}]$ (LL) and ALOS Palsar FBD with $\mathrm{RGB}=[\mathrm{HH}, \mathrm{HV}, \mathrm{NDI}](\mathrm{LR})$.
2010 dual-polarization mosaics from ASAR APS in VV and $\mathrm{VH}$ and Palsar FBD in $\mathrm{HH}$ and $\mathrm{HV}$ polarization were complemented with a band representing the normalized difference index (NDI) describing the ration between the copolarization $\mathrm{XX}$ (i.e. $\mathrm{HH}$ or $\mathrm{VV}$ ) and cross-polarization $\mathrm{XY}$ (i.e. $\mathrm{HV}$ or $\mathrm{VH}$ ) backscatter as:

\section{$\mathrm{NDI}=(\mathrm{XX}-\mathrm{XY}) /(\mathrm{XX}+\mathrm{XY})$}

\subsection{Forest/Non-Forest (FNF) Maps}

\subsubsection{FNF from optical sensors.}

For deriving the optical forest/non-forest map, a supervised maximum likelihood classification method was selected for the optical mosaics, except for the RapidEye mosaic, where a support vector machine classification was used. The NDVI of each one was added as an additional synthetic band to improve the classification. Since this methodology needs "ground-truth" data to train the algorithm, training polygons have been extracted from 2009/2010 Kompsat-2 VHR images for Landsat 2001 and ALOS Avnir-2 for 2010. Training polygons were extracted dividing each image with a diagonal: training samples were extracted from the upper part, while the lower part was kept aside for the subsequent validation steps. Samples from six classes were recollected and finally combined to output classes: 'forest' and 'non-forest'. This approach is mandatory to reduce the standard deviation between classes. The class forest consisted of sparse forest and dense forest and the class 'nonforest' was a combination of bare soil, grassland, shrubs and cleared forest. However due to bad spectral separability of some classes with respect to others, water and urban classes were masked out from the classification. Therefore, the final classification is the result of the combination of the different classes on the non-masked area. Finally, to avoid the salt and pepper effect a majority Kernel filter with $5 \times 5$ pixel size was applied.

RapidEye classification is based on training polygons, based on the original $5 \mathrm{~m}$ resolution RapidEye images. Samples were created using an adjusted stratified sampling grid with 1824 square polygons of $6.25 \mathrm{ha}$ area each (Fig 4). Within each polygon final training points were randomly sampled. The classification used a support vector machine (SVM) classifier with a 100 time bootstrapping with a complete set of 23711 samples. The initial 9 classes were merged to produce the FNF map and the final map conformed to the FAO minimum forest area definition where forest clusters smaller than 0.5 ha were excluded from the forest class. The 2012 FNF map (Fig 4 right) was based on the 158 RapidEye scenes between 2011 and 2013 aggregated to a ground sample distance (GSD) mosaic of $30 \mathrm{~m}$. Fig. 5 shows the FNF maps for Landsat 2001, ALOS Avnir-2 2010 and RapidEye 2012 from left to right. 


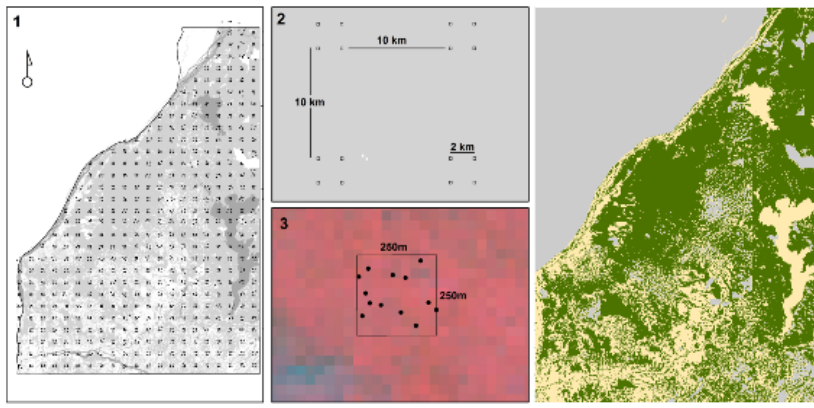

Figure 4. Overview of the training samples (1,2 and 3$)$ used for production of RapidEye FNF map for 2012 (Fig. 5).
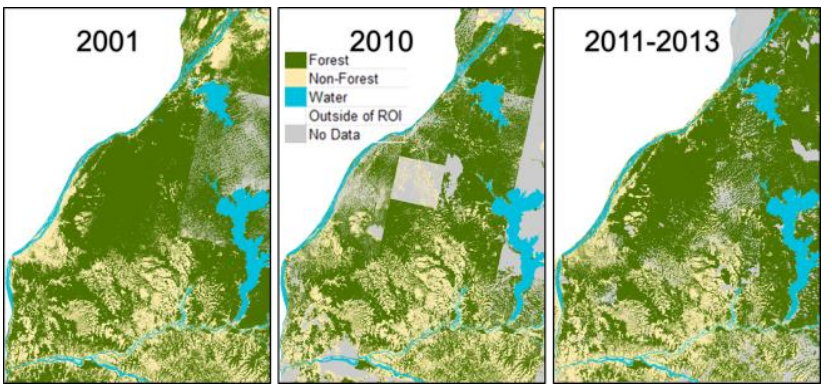

Figure 5. Optical FNF maps (from left to right) based on Lansat-7 ETM+ for 2001, ALOS Avnir-2 for 2010 and RapidEye for 2012.

\subsubsection{FNF from SAR sensors.}

For deriving the SAR based FNF maps, only land cover classes were used, which could be clearly identified during the field campaign in spring 2013. Direct correspondence with the IPCC classes or other definitions within the ReCover project was not necessary, since the only purpose of those classes is the subsequent separability into the super-classes forest and nonforest. Observations from the transect measurement performed during the field campaign were extrapolated to training polygons for subsequent classifications, supported by RapidEye VHR data from the years 2011-2013, ALOS Avnir-2 acquisitions from 2010 and GoogleEarth imagery. A time series analysis was performed on available ERS-2, Envisat ASAR and ALOS Palsar data in order to determine the optimal acquisition date for classification to reduce humidity effects on the backscatter coefficient. Furthermore, the time series analysis indicates that the exploitation of an artificially created bitemporal feature space extension could improve the classification result. FNF maps were finally produced using a Maximum-Likelihood classification based on the training polygons of all classes. Water bodies were masked using the water mask extracted from the FACET map (OSFAC, 2010).

2000 FNF map (Fig 6a): Due to the general poor ERS-2 data quality a mono-variate approach generated only poor results and separabilities. For that reason, a feature space extension by including ASAR WSM data from the year 2002 was envisaged. Despite the same polarization and wavelength, the eminent difference in the sensor's incidence angle, this approach led to acceptable Jeffries-Matusita (JM) separabilties.

2005 FNF map (Fig 6b): FNF classification for the year 2005 was based on the average backscatter from 25 Envisat ASAR WS scenes from 2004 and 2005. The large amount of applied scenes guarantees proper multi-temporal speckle filtering plus the possibility for dividing acquisitions into wet and dry season for a feature space extension. Especially the non-forest classes displayed a distinct seasonal behaviour, which led again to a better JM separability in the 2-dimensional feature space.

2010 FNF map (Fig 6c): For producing the 2010 FNF map both $\mathrm{C}$ - and L-band acquisitions were available. Due to strong speckle effects caused by the high sensitivity of C-band data for vegetation and moisture content of vegetation and soils, no improvement could be achieved by incorporating C-band data. The presence of dual-pol Palsar (FBD) data for the dry season and single-pol Palsar (FBS) data for the wet season in the period from 2009 to 2010 allowed the evaluation of a 4dimensional feature space. As for the 2005 FNF classification, some classes display a distinct seasonal behaviour, improving yet again the JM separability.
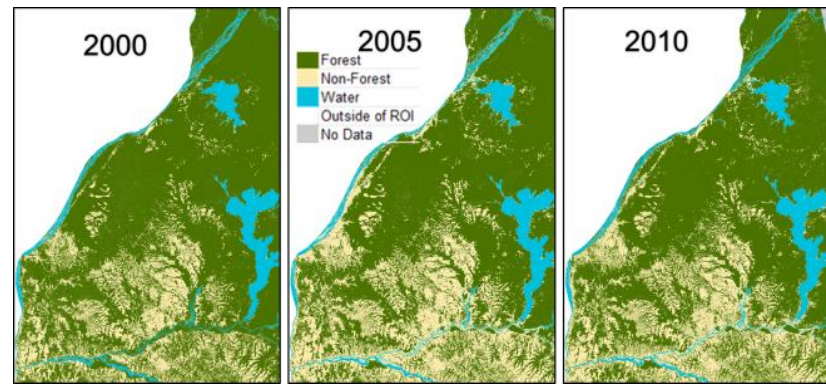

Figure 6. SAR-based FNF maps from ERS-2 SAR and Envisat ASAR WS for 2000 (a), Envisat ASAR WS for 2005 (b) and ALOS Palsar FBD/FBS for 2010 (c).

\subsection{0-2010 Forest Change Map}

2000-2010 forest change maps were produced based on both optical and SAR FNF maps individually. As the sensors used in 2000 and 2010 differ in several aspects (resolution, acquisition geometry, sensibility, etc.), Landsat and RapidEye for optical and ERS-2/Envisat ASAR WS and ALOS Palsar for SAR, respectively, their derived change based on the classified FNF products represents rather a sum of their respective errors than the true forest change. The single sensor type forest change products therefore highly overestimate the forest change. However, combining both, the optical and SAR forest change maps into one multi-sensor optical/SAR forest change product by accepting only forest change that occurs in both single sensor type products reduces the noise induced by the sensor difference and reveals at least the hotspots of deforestation mainly in the south of the region of interest. Fig. 7 shows the multi-sensor forest change result based on the combination of optical and SAR FNF maps from 2000 and 2010.

\subsection{Above Ground Forest Biomass (AGB) Map}

To further improve the result of the first biomass map from the first iteration (Haarpaintner et al., 2012; Desclée et al., 2014), which was based on Landsat and 2003-2009 ICESat/GLAS data, a stratification of different types of forest cover was carried out. The RapidEye image mosaic compiled at $30 \mathrm{~m}$ resolution was used for the classification of different types of forest cover. These types were closed forest, open forest and inundated forest. The computation of AGB was achieved in three major steps. In a first step a classification was performed on the optical RapidEye mosaic. In the second step 2003-2009 ICESat/GLAS data was grouped by forest based on the classification result. In a third step the vegetation height derived from ICESat GLAS was interpolated within each class and finally converted to AGB by applying an allometric equation. 


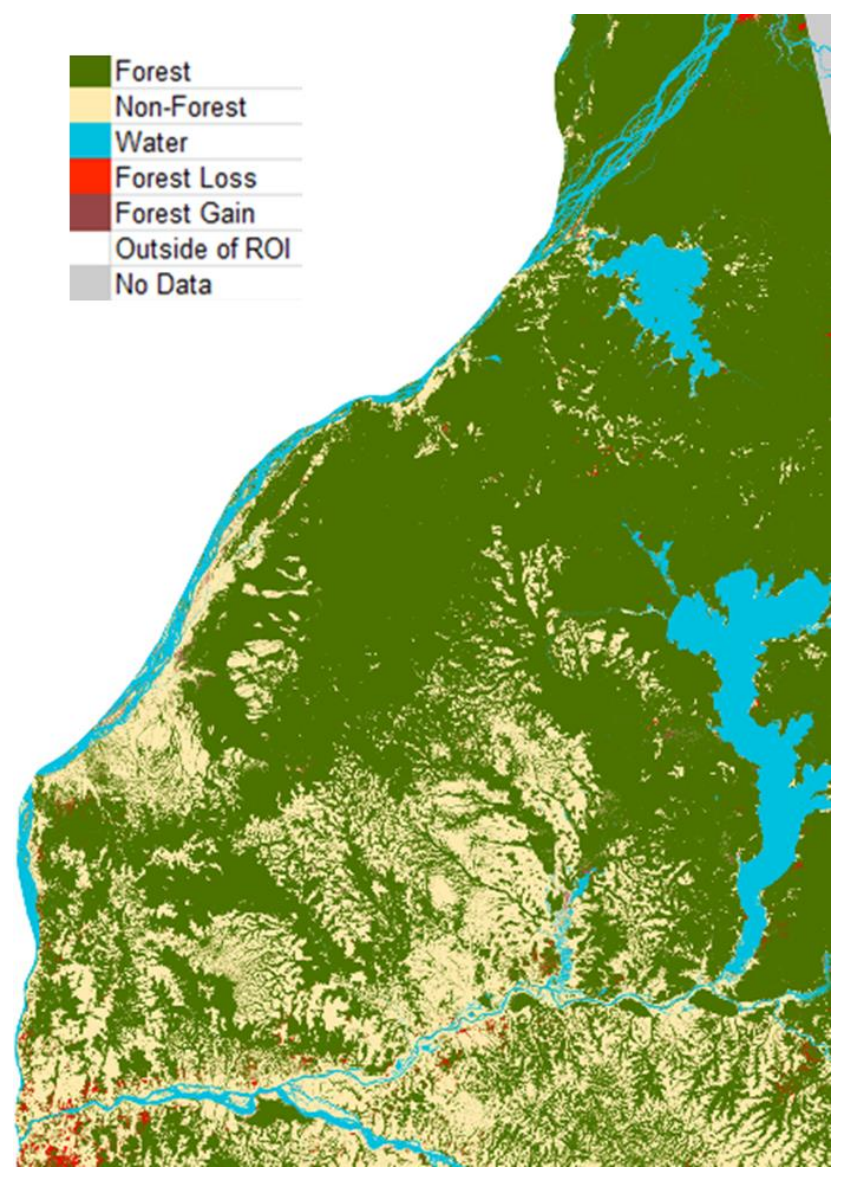

Figure 7. 2000-2010 Forest change map derived from optical and SAR based FNF maps from 2001/2012 and 2000/2010, respectively.

The allometric relation of vegetation height and AGB for tropical forests in sub-Saharan Africa (Saatchi et al., 2011) was applied. The AGB map is shown in Fig. 8.

\section{VALIDATION}

FNF products were validated using half of the training polygons that were extracted during the optical FNF classification process from 2001 Landsat data for the year 2000 products and 20092010 very high resolution optical data from Kompsat- 2 for the 2005 and 2010/2012 products. Table 1 resumes the validation results from both the first and second iteration. There has been a slight improvement in accuracy for all FNF products but the 2010 ALOS Avnir-2 FNF product. Validation of the forest change and AGB products could not be performed during the ReCover project because of lack of data.

Table 1: FNF product accuracy in percent.

\begin{tabular}{|l|c|c|c|}
\hline \multicolumn{1}{|c|}{ FNF Map } & $\begin{array}{c}\text { Classification } \\
\text { method }\end{array}$ & $\begin{array}{c}\text { Accuracy } \\
\text { 1st iteration }\end{array}$ & $\begin{array}{c}\text { Accuracy } \\
\mathbf{2}^{\text {nd }} \text { iteration }\end{array}$ \\
\hline 2001 Landsat-7 ETM+ & MLH & $91.22 \%$ & $91.69 \%$ \\
\hline 2010 ALOS Avnir-2 & MLH & $85.19 \%$ & $84.47 \%$ \\
\hline 2011-2013 RapidEye & SVM & N/A & $86.74 \%$ \\
\hline 1999-2002 ERS-2/ASAR WS & MLH & $75.63 \%$ & $88.67 \%$ \\
\hline 2004/2005 ASAR WS & MLH & $85.19 \%$ & $87.62 \%$ \\
\hline 2010 ALOS Palsar & MLH & $88.11 \%$ & $88.48 \%$ \\
\hline
\end{tabular}

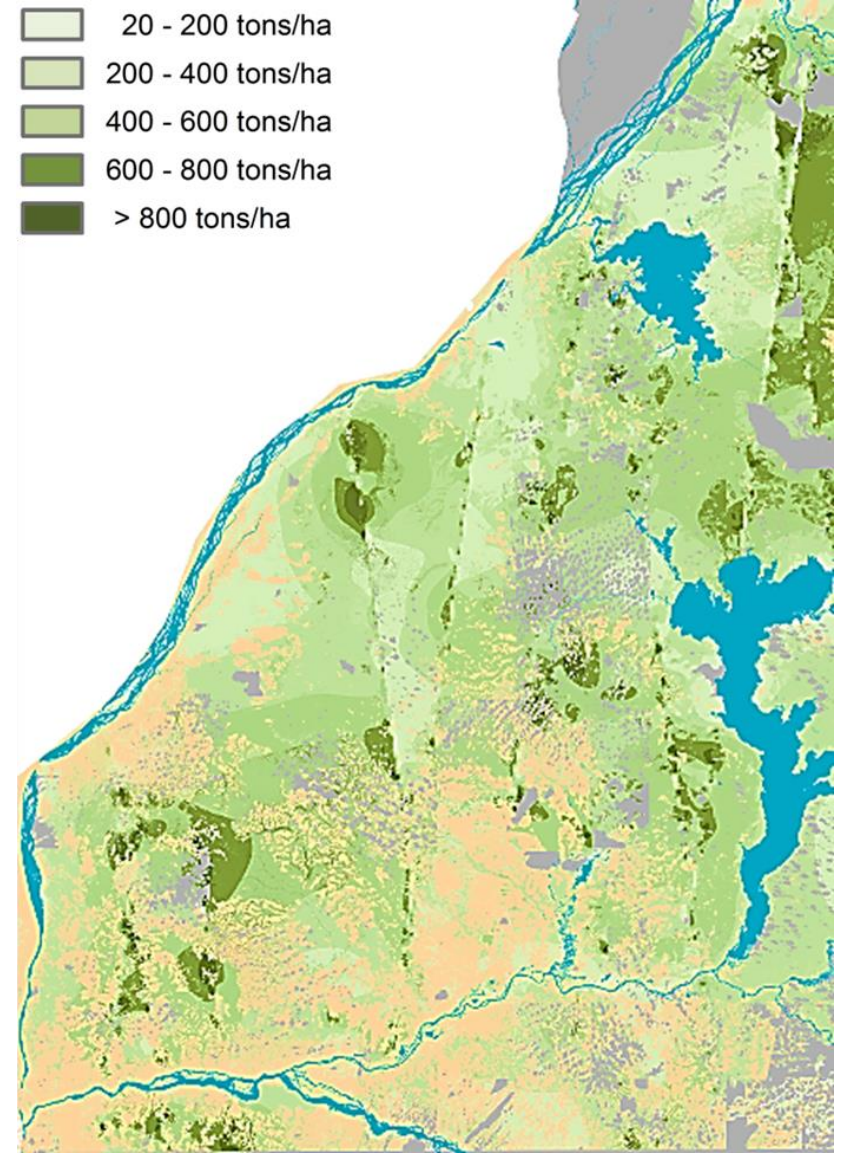

Figure 8. Above ground biomass based on 2003-2009 ICESat GLAS data. Beige is non-forest and grey are clouds.

\section{SERVICE ASSESSMENT \& CONCLUSION}

According to the user's (OSFAC's) product assessments, especially the cloud-independent SAR based products are of high quality and represent a novelty for this region. SAR results were also slightly more accurate than optical results for the FNF maps. Decadal forest change is difficult to extract with high accuracy because of sensor differences for the SAR sensors and forest change detection based on FNF maps rather sum up the errors of the individual FNF maps than detect real forest change. A multi-sensor approach however showed that hot spots of deforestation could be detected by combining optical and SAR FNF maps of the different years.

At this stage, these products represent an additional data source for analysis for evaluating nation-wide products like the FACET atlas (OSFAC, 2010) and an additional data in the portfolio of OSFAC.

However, those data are also available to be integrated into the National Forest Monitoring System (NFMS) and future operationalization in the NFMS could be considered with focus on historical and upcoming SAR data from the European Sentinel-1 and Japanese ALOS-2 satellites that are to be launched in 2014. 


\section{ACKNOWLEDGEMENTS}

Thanks to T. Häme (VTT) for leading the ReCover consortium, Y. Larsen, H. Hindberg and M. Kohling (all Norut) for their technical support in SAR processing and D. Pedrazzani (formerly at GMV, now at ESA/ECSAT) for her contribution. Satellite data has been provided through a GSC-DA grant from ESA and JAXA, Landsat from USGS and ICESat GLAS from NSIDC. ReCover is funded by the European Commission EU FP7-SPACE-2010-1 program under grant agreement nr. 263075. Additional PhD support at Norut was funded through grant nr. 204430/E40 by the Norwegian Research Council.

\section{REFERENCES}

Chavez, P. S., 1996. Image-based atmospheric correctionrevised and improved. Photogrammetric Engineering and Remote Sensing, 62 (9), pp. 1025-1036.

Desclée, B., Ph. Mayaux, M. Hansen, P. Lola Amani, C. Sannier, B. Mertens, T. Häusler, R. Ngamabou Siwe, H. Poilvé, V. Gond, M. Rahm, J. Haarpaintner, and J-P. Kibambe Lubamba, 2014. Chapter 1. Evolution of forest cover at a national and regional scale and drivers of change. In "The Forests of the Congo Basin - State of the Forest 2013. "by C. de Wasseige, J. Flyn , D. Louppe, F. Hiol Hiol, and Ph. Mayaux (eds.), Weyrich Édition, Belgium, 328 p., Legal deposit: D/2014/8631/42, ISBN: 978-2-87489-299-8, pp. 21-46.

Einzmann, K., J. Haarpaintner, and Y. Larsen, 2012. Forest monitoring in Congo Basin with combined use of SAR C- \& Lband. Proceedings of the IEEE International Geoscience and Remote Sensing Symposium 2012, 22-27 July, Munich, Germany, IEEE Catalog Number: CFP12IGA-USB, ISBN: 9781-4673-1158-8, pp. 6573-6576.

Haarpaintner, J., K. Einzmann, D. Pedrazzani, M.T. Mateos San Juan, M. Gómez Giménez, J. Heinzel, F. Enßle, and L. Mane, 2012. Tropical Forest Remote Sensing Services for the Democratic Republic of Congo case inside the EU FP7 'ReCover' project (1st iteration). Proceedings of the IEEE International Geoscience and Remote Sensing Symposium 2012, 22-27 July, Munich, Germany, IEEE Catalog Number: CFP12IGA-USB, ISBN: 978-1-4673-1158-8, pp. 6392-6395.

Haarpaintner, J. and F. Enßle, 2015. Validating Optical and SAR Satellite-Based Forest Maps with Remotely Piloted Aerial Systems in Mai-Ndombe District (DRC). Poster at the ForestSAT2014 conference, 4-7 Nov. 2014, Riva del Garda (TN), Italy. Manuscript submitted to the Special Issue ForestSAT2014 in EuJRS.

Häme, T., L. Sirro, E. Cabrera, J. Haarpaintner, J. Heinzel, J. Hämäläinen, B. DeJong, F. Paz Pellat, D. Pedrazzani, and J. Reiche, 2012. Chapter 8: ReCover: Services for the Monitoring of Tropical Forest to Support REDD+. In: 'Let's Embrace Space, vol. II' (Eds. R. Schulte-Braucks, P. Breger, H. Bischoff, S. Borowiecka, \& S. Sadiq), Publication office of the European Union, Luxembourg, ISBN 978-92-79-22207-8, doi: 10.2769/31208, pp. 106-114.

Hansen, M.C., D. Roy, E. Lindquist, C.O. Justice, and A. Altstatt, 2008. A method for integrating MODIS and Landsat data for systematic monitoring of forest cover and change in the Congo Basin. Remote Sensing of Environment, 112, 2495-2513.
Hansen, M. C., P. V. Potapov, R. Moore, M. Hancher, S. A. Turubanova, A. Tyukavina, D. Thau, S. V. Stehman, S. J. Goetz, T. R. Loveland, A. Kommareddy, A. Egorov, L. Chini, C. O. Justice, and J. R. G. Townshend, 2013. High-Resolution Global Maps of 21st-Century Forest Cover Change. Science 342, pp.850-53. Data available on-line from: http://earthenginepartners.appspot.com/science-2013-globalforest.

OSFAC, 2010. Monitoring the forests of Central Africa using remotely sensed data sets (FACET), 2010. Forest cover and forest cover loss in the Democratic Republic of Congo from 2000 to 2010. South Dakota State University, Brookings, South Dakota, USA. ISBN: 978-0-9797182-5-0.

Häme, T. and A. Lönnqvist, 2011. Science-based remote sensing services to support REDD and sustainable Forest management in the tropical region. Proceedings of Hungarian Space Conference, Budapest, Hungary. May 2011.

Larsen, Y., G. Engen, T.R. Lauknes, E. Malnes, and K.A. Høgda, 2005. A generic differential interferometric SAR processing system, with applications to land subsidence and snow-water equivalent retrieval. Proc. FRINGE 2005, Frascati, Italy, Nov 28 - Dec 2, 2005.

Pedrazzani, D., M.T. Mateos San Juan, M. Gómez Giménez, J. Haarpaintner, K. Einzmann, and L. Mane, 2012. Potential Applications of Sentinel-2 Data To Forest Monitoring Services In Support to REDD Activities: The Democratic Republic Of Congo Case Within Recover Project. Proceedings of ESA Sentinel-2 Preparatory Symposium, Frascati, Italy, 23-27 April 2012.

Saatchi, S.S., N.L. Harris, S. Brown, M. Lefsky, E.T.A. Mitchard, W. Salas, B.R. Zutta, W. Buermann, S.L. Lewis, S. Hagen, S. Petrova, L. White, M. Silmann, and A. Morel, 2011. Benchmark map of forest carbon stocks in tropical regions across three continents. Proceedings of the National Academy of Sciences of the United States of America, 108, pp. 98999904.

Shimada, M., and O. Takahiro, 2010. Generating Large-Scale High-Quality SAR Mosaic Datasets: Application to PALSAR Data for Global Monitoring. IEEE journal of selected topics in applied earth observations and remote sensing, 3(4), pp. 637656.

Ulander, L., 1996. Radiometric slope correction of synthetic aperture radar images. IEEE Transactions on Geoscience and Remote Sensing,34(5), pp.1115-1122. 